\title{
Esculpindo Superfícies de Polímeros com Luz
}

Em 1995, dois grupos de pesquisa, um deles liderado pelos Profs. Sukant Tripathy e Jayant Kumar, na Universidade de Massachusetts em Lowell, EUA, e o outro pela Profa. Almeria Natansohn, no Canadá, relataram a possibilidade de alterar significativamente a superfície de polímeros contendo cromóforos de azobenzeno, criando grades de relevo tridimensionais. Esta propriedade, característica dos azopolímeros, vem sendo estudada no Brasil pelos Grupos de Polímeros Bernhard Gross e de Óptica do IFSC.

A inscrição de grades tem sido feita em materiais contendo grupos azobenzênicos. A figura mostra uma grade típica, obtida a partir da incidência de um padrão de interferência de dois feixes de laser sobre um filme automontado de poli(alilamina hidroclorada), $\mathrm{PAH}$ e o azocorante amarelo brilhante (brilliant yellow, BY) (veja box). A modulação é resultado de um processo equivalente ao esculpir da superfície do polímero, gerando transporte de massa em dimensões micrométricas (note que a grade da figura tem um período de modulação de $2 \mu \mathrm{m}$ ). A amplitude da modulação pode atingir $1 \mu \mathrm{m}$ ou mais, para filmes com espessura de alguns micra. Tal transporte é surpreendente porque a inscrição da grade é feita à temperatura ambiente, para polímeros com temperatura de transição vítrea $(\mathrm{Tg})$ de 100 a $190^{\circ} \mathrm{C}$. Não se deveria, portanto, esperar mobilidade das cadeias - principalmente considerando que as baixas intensidades de laser utilizadas (menores que $100 \mathrm{~mW} / \mathrm{cm}^{2}$ ) não causam aquecimento do filme. A formação de grades, nessas condições, é um processo inteiramente fotônico, que pode ser explicado por um modelo segundo o qual os cromóforos sofrem uma força que é proporcional ao gradiente do cam-

po elétrico (óptico). Este modelo, desenvolvido pelo Grupo de Lowell, EUA, foi testado extensivamente fornecendo a adequada dependência com a polarização dos feixes de laser. A mobilidade das cadeias, que permite o transporte de massa, é oriunda dos processos eficientes de fotoisomerização trans-cis-trans dos cromóforos de azobenzeno. Ao ab-
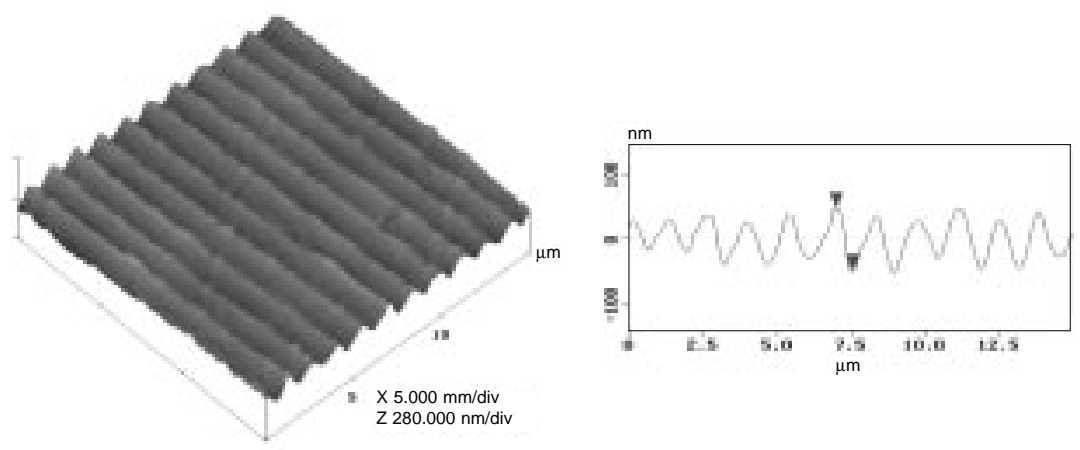

Grade fabricada pelos doutorandos Valtencir Zucolotto, Newton Barbosa e Joatan Rodrigues no grupo de Óptica do IFSC. Período de $2 \mu \mathrm{m}$, profundidade de $90 \mathrm{~nm}$, sobre filme automontado de PAH/BY. Filmes automontados são produzidos pela adsorção alternada de espécies catiônicas e aniônicas sobre um substrato sólido. O processo de fotoinscrição nestes filmes é possível devido às interações eletrostáticas entre as camadas de um polímero inerte ao laser e as camadas contendo corantes de azobenzeno. Durante a movimentação dos cromóforos, arrastam-se também as cadeias poliméricas, modulando a superfície.

sorver a luz do laser, os cromóforos são excitados de sua conformação de mais baixa energia trans para a conformação cis. Eles relaxam de volta à forma trans, termicamente ou mesmo por excitação óptica, uma vez que os cromóforos continuam absorvendo um pouco de luz mes- téria, as grades de difração assim produzidas encontram aplicações em fotônica. Estas incluem a produção de dispositivos ópticos, como guias de onda ou de acoplamento de luz, memória óptica e fabricação de hologramas. No Brasil, os Grupos de Polímeros Prof. 
Bernhard Gross e de Óptica, do IFSC, iniciaram pesquisas em grades de relevo em 1998, tendo sido os primeiros a apresentar grades inscritas em filmes LangmuirBlodgett (LB) de azopolímeros. Mais recentemente, os signatários desta nota realizaram estágio no Center for Advanced Materials, Lowell, e vêm continuando pesquisas no IFSC, principalmente no tocante aos mecanismos envolvidos na fabricação de grades em sistemas poliméricos automontados e em filmes do tipo LB.

Para mais detalhes:

1. Viswanathan, N.K., Balasubramanian, S., Li, L., Tripathy, S.K., Kumar, J., A detailed investigation of the polarization-dependent surfacerelief-grating formation process on azo polymer films, Japanese J. Appl. Phys. Part 1-Regular Papers Short Notes \& Review Papers , 38, pp. 5928-5937 (1999).

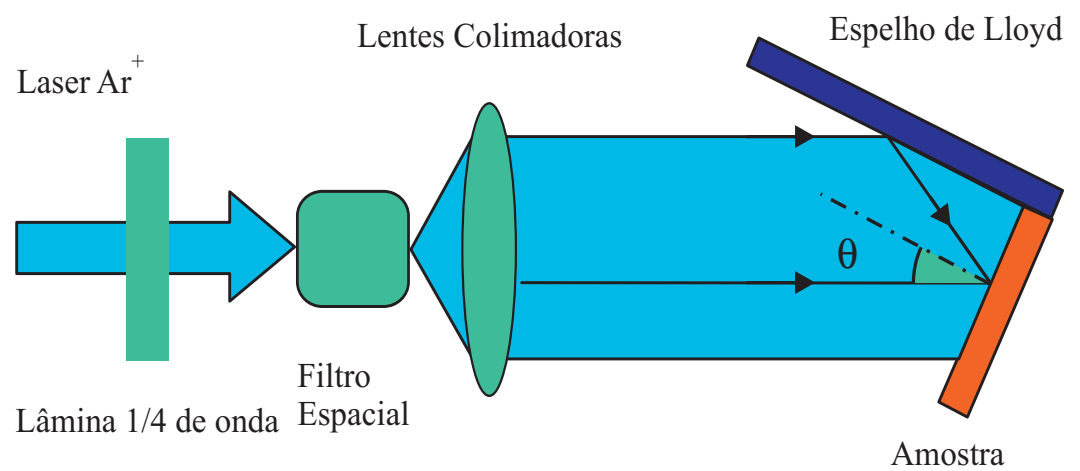

O Procedimento experimental ilustrado na figura consiste em incidir na amostra dois feixes de laser provenientes de uma mesma fonte, mas que percorrem caminhos ópticos diferentes, de maneira a criar na superfície da amostra um padrão de interferência bem definido. As cadeias poliméricas tendem a se afastar das regiões mais iluminadas, levando a uma grade de relevo que está fora de fase com o padrão de interferência. Ou seja, os picos das grades correspondem aos vales da distribuição de energia luminosa sobre a amostra.

2. Mendonca, C.R., Dhanabalan, A., Balogh, D.T., Misoguti, L., dos Santos, D.S., Pereira-da-Silva, M.A., Giacometti, J.A., Zilio, S.C., Oliveira, O.N., Optically induced birefringence and surface relief gratings in compos- ite Langmuir-Blodgett (LB) films of poly[4'-[[2-methacryloyloxy) ethyl] ethylamino] -2-chloro-4nitroazobenzene] HPDR13) and cadmium stearate, Macromolecules, 32, pp. 1493-1499 (1999).

Matéria elaborada por Valtencir Zucolotto e Osvaldo N. Oliveira Jr., Instituto de Física de São Carlos, USP, C.P. 369, CEP:13560-970, São Carlos, SP, tel.(16) 273-9825, e-mail: zuco@if.sc.usp.br, chu@if.sc.usp.br. 